\title{
How Doratomyces stemonitis copes with Benzoxazolin-2(3H)-one (BOA), its derivatives and detoxification products
}

\author{
Nataliya Voloshchuk ${ }^{1}$, Mona Knop ${ }^{2}$, Thomas Colby ${ }^{3}$, Erich Kombrink ${ }^{3}$, Lothar Hennig ${ }^{4}$, Diana Hofmann ${ }^{5}$, \\ Dieter Sicker ${ }^{4}$, Andrej Gryganski ${ }^{1}$ and Margot Schulz ${ }^{2}$ \\ ${ }^{1}$ Department of Phytopathology, National University of Agriculture, Geroiv Oborony Str. 13, Kiew, Ukraine \\ ${ }^{2}$ Institut für Molekulare Physiologie und Biotechnologie der Pflanzen, Universität Bonn, Karlrobert Kreiten Str. 13, Bonn, Germany \\ ${ }^{3}$ Max-Planck-Institut für Züchtungsforschung, Carl von Linné Weg 10, 50829 Köln, Germany \\ ${ }^{4}$ Institut für Organische Chemie, Universität Leipzig, Johannisallee 29, 04103 Leipzig, Germany \\ ${ }^{5}$ Institut für Analytische Chemie, Universität Leipzig, Johannisallee 29, 04130 Leipzig, Germany
}

Summary. Doratomyces stemonitis (Hyphomycetales, Dematiaceae) is a saprotrophic fungus belonging to the mycobiota of the cereal rhizosphere. The fungus is able to metabolize benzoxazolin-2- $(3 H)$-one and a variety of its derivatives including higher plant detoxification products, microbial degradation products and the chemically rather stable 2-amino-(3H)-phenoxazin-3-one. D. stemonitis can use all of these compounds as sole C-sources but their utilization, especially that of microbial degradation products and 2-amino-(3H)-phenoxazin-3-one, seems to be highly energy consuming, resulting in slow mycelium growth and a change of colony morphology. Benzoxazolin-2- $(3 H)$-onederived compounds induce the synthesis of different isoforms of a glycosylated protein with sequence homologies to the endo-1,3- $\beta$-glucanase Asp f2, an allergen from Aspergillus fumigatus and other Asp f2-like proteins e.g., from Verticillium dahliae or PRA1 antigen from Candida albicans. The induction of the protein is regarded as a stress response.

Key words. allelopathy-Doratomyces stemonitis - benzoxazolin-2 $(3 H)$-one - glucoside carbamate - 2-amino-3Hphenoxazin-3-one metabolization - allergen Asp f 2 similar protein - endo-1,3- $\beta$-glucanase

\section{Introduction}

Benzoxazinone glucosides are secondary products of several Poaceae and of a few species belonging to dicotyledoneous families (Alipieva et al. 2003; Gierl \& Frey 2001, Sicker et al. 2000; Sicker \& Schulz 2002). They can be released into the environment by plant rotting or by root exudation. The aglycones are compounds with biocidice properties and are therefore of interest for the development of ecologically oriented pest control in agriculture (Bravo \& Lazo 1996; Macias et al. 2005). The aglycones are not stable in aqueous solution but are converted via ring contraction and

*Correspondence to: Margot Schulz, e-mail: ulp509@uni-bonn.de release of formic acid to benzoxazolin-2-(3H)-ones. These products are still bioactive molecules. For example, benzoxazolin-2-(3H)-one (BOA) is thought to be the major phytotoxic component of rye mulch (Barnes \& Putnam 1987). Benzoxazolin-2-(3H)-ones are more stable than their precursors 2,4-dihydroxy-substitued 2H-1,4-benzoxazin3(4H)-ones, with 2,4-dihydroxy-2H-1,4-benzoxazin-3 (4H)-one (DIBOA) and 2,4-dihydroxy-7-methoxy-2H-1, 4-benzoxazin-3(4H)-one (DIMBOA) as main representatives (fig. 1). Nevertheless, they are degraded by microorganisms able to cleave the heterocycle. One of the resulting products, 2-aminophenol, undergoes oxidative dimerization to 2-amino-3H-phenoxazin-3-one which has been isolated from soil samples (Gagliardo \& Chilton 1992). Recent investigations showed that the compound was persistent in wheat crop soils over a period of three months (Macias et al. 2005).

Several bacteria and fungi have been described which are able to degrade benzoxazolin-2-(3H)-one (Gagliardo \& Chilton 1992; Friebe et al. 1996). A number of fungal plant pathogens are sensitive to benzoxazinones and benzoxazolinones whereas others, including several Fusarium species, were found to be less affected since they are able to degrade these allelochemicals (Morrissey \& Osbourn 1999).

An endophytic fungus from Aphelandra tetragona (this plant species is one of the rare dicots containing benzoxazinones as secondary compounds) was found to produce a number of hydroxylated 2-amino-3H-phenoxazin-3-one derivatives from 2-hydroxy-2H-1,4-benzoxazin-3(4H)-one (HBOA) and BOA (Baumeler et al. 2000; Zikmundova et al. 2002a; Zikmundova et al. 2002b). The maize endophytic fungus Fusarium verticillioides ( $F$. moniliforme) and several wheat-associated fungi transform BOA and the 6-methoxybenzoxazolin-2-(3H)-one (MBOA) into N-(2hydroxyphenyl)-and N-(2-hydroxy-4-methoxyphenyl)malonamic acid (HPMA and HMPMA, respectively). (Glenn et al. 2003; Yue et al. 1998; Friebe et al. 1998). In Fusarium verticillioides two genes have been identified, $F D B 1$ and $F D B 2$, that are responsible for BOA and MBOA detoxification. The $F D B 1$ encoded enzyme is proposed to hydrolyze the oxazolinone ring, which in combination with 
<smiles>O=c1[nH]c2ccccc2o1</smiles><smiles>O=c1[nH]c2ccc(O)cc2o1</smiles><smiles>COc1ccc2[nH]c(=O)oc2c1</smiles><smiles>O=C1OC2OC(CO)C(O)C(O1)N2c1ccccc1O</smiles><smiles>Nc1ccccc1O</smiles><smiles>CC(=O)Nc1ccccc1O</smiles><smiles>O=C(O)CC(=O)Nc1ccccc1O</smiles>

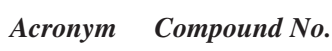

BOA

BOA-6-OH

2

6-hydroxybenzoxazolin-2(3H)-one

MBOA

3

6-methoxybenzoxazolin-2-(3H)-one

4

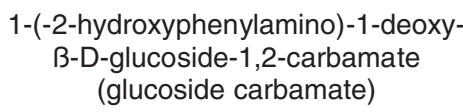

1-(-2-hydroxyphenylamino)-1-deoxyB-D-glucoside-1,2-carbamate (glucoside carbamate)

5

2-aminophenol

AAP

6

2-acetamidophenol

oHPMA
$\mathrm{N}$-(2-hydroxyphenyl) malonamic acid

Fig 1. (continued)

decarboxylation results in 2-aminophenol. The enzyme encoded by $F D B 2$ is thought to use 2-aminophenol as a substrate for HPMA synthesis since in FDB1/fdb2 mutants, 2 -acetamidophenol is produced instead of HPMA. This implies that BOA and probably numerous other allelochemicals too, induces alterations in fungal gene expression followed by de novo syntheses of proteins, which may be, for instance, involved in BOA degradation pathways. At present, no study is available where the influence of benzoxazinoids on fungal protein pattern has been investigated.

Many plants also have the potential to diminish harmful effects of BOA by detoxification, especially cereals and other grasses, as well as European weeds that co-exist with benzoxazinones-containing crops like rye and wheat (Schulz \& Wieland, 1999; Sicker et al. 2001). In plants, two detoxification pathways for BOA are known at present, the first one leads to the accumulation of BOA-6-O-glucoside via 6-hydroxybenzoxazolin-2( $3 H$ )-one (BOA-6-OH), an intermediate that is toxic to higher plant radicle growth. The second detoxification pathway results in 1-(-2-hydroxyphenylamino)-1-deoxy- $\beta$-D-glucoside-1,2-carbamate (glucoside carbamate) production. This pathway appears to be the more effective one since in bioassays, glucoside carbamate was found to be not toxic for higher plants at 
<smiles>Nc1cc2nc3ccccc3oc-2cc1=O</smiles><smiles></smiles>

H1
Acronym Compound No.

8

2-amino-3H-phenoxazin-3-one
Fig. 1 Structures, acronyms and names of DIBOA, DIM$\mathrm{BOA}$ and the compounds used for incubations

2-aminophenol-N-B-Dglucopyranoside<smiles>O=C1C(O)Oc2ccccc2N1O</smiles>

DIBOA

2,4-dihydroxy-2H-1,4-benzoxazin-

3(4H)-one

DIMBOA

2,4-dihydroxy-7-methoxy-2H-1,4benzoxazin-3(4H)-one

\section{Material and Methods}

$\mathrm{O}$ - glucoside was found in all species tested, glucoside carbamate production was found to be the major detoxification pathway in Poaceae. In Zea mays glucoside carbamate can be further glucosylated yielding gentiobioside carbamate or malonylated to malonyl glucoside carbamate (Hofmann et al. 2006). At least a portion of these detoxification products does not stay within the root, the most important plant organ for BOA detoxification, but is exuded. Thus, not only BOA from benzoxazinoid - producing species but also BOA detoxification products are released into the soil. This raises the question whether or not any soil- or root-colonizing micro-organisms exist that are able to metabolize or convert the degradation products released by the plants, including highly toxic BOA$6-\mathrm{OH}$, and whether the compounds influence the protein pattern of the micro-organisms.

Promising organisms in this respect are fungi belonging to the mycobiota of the cereal rhizosphere. In this study we tested one member of this group, Doratomyces stemonitis (Hyphomycetales, Dematiaceae), a saprotrophic fungus living on plant material in soils of Europe and North America, for its ability to cope with MBOA, BOA, BOA detoxification products from higher plants and additional BOA derived compounds. We were particularly interested in alterations of fungal protein patterns in response to allelochemical treatment.

Doratomyces stemonitis was obtained from the collection of D.K. Zabolotny, Institute of Microbiology and Virology, National Academy of Sciences of the Ukraine. Mycelial plugs from agar plates (discs $1 \mathrm{~cm}$ in diameter with $0.5 \mathrm{mg}$ mycelium) were transferred into $250 \mathrm{ml}$ flasks with $100 \mathrm{ml}$ sterilized Czapak medium. For growth tests (series A), the incubations were performed in the dark with complete medium and medium lacking sucrose at $25{ }^{\circ} \mathrm{C}$ (controls), and with addition of either BOA (1), BOA-6-OH (2), MBOA (3), glucoside carbamate (4), 2-aminophenol (5), 2-acetamidophenol (AAP, 6), N-(2-hydroxyphenyl)-malonamic acid (oHPMA, 7), 2-amino3H-phenoxazin-3-one (8), or 2-aminophenol-N- $\beta$-D-glucopyranoside (H1, 9), (fig. 1). The compounds were found to be stable at $25^{\circ} \mathrm{C}$ in the dark and under sterile conditions over a period of two months. Each compound was tested individually. The concentration of each tested compound was $10 \mu \mathrm{mol}$, the one of 2-amino$3 \mathrm{H}$-phenoxazin-3-one was $1 \mu \mathrm{mol}$. For metabolism studies the incubations were performed in the same manner, but with medium lacking sucrose using mycelia previously cultivated in presence of sucrose (series B: BOA and higher plant detoxification products $\mathbf{1}, \mathbf{2}, \mathbf{3}, \mathbf{4}$; series $\mathrm{C}$ : microbial compounds $\mathbf{6}, \mathbf{7}, \mathbf{8}$, and the synthetic compound 9). For 2-dimensional electrophoresis mycelia were incubated 
without sucrose. BOA and 2-acetamidophenol were from Aldrich, MBOA, BOA-6-OH, N-(2-hydroxyphenyl) malonamic acid and 1-(-2-hydroxyphenylamino)-1-deoxy- $\beta$-D-glucoside 1,2-carbamate (glucoside carbamate) were synthesized as previously described (Sicker, 1989; Wieland et al. 1999; Friebe et al. 1998; Wieland et al. 1998; Sicker et al. 2001). Hitherto undescribed 2-aminophenol-N- $\beta$-Dglucopyranoside was obtained by the following method: 2-Aminophenol (1.9 g, 10 mmoles) and D-glucose (1.8 g, 10 mmoles) were heated in ethanol $(30 \mathrm{ml})$ under reflux and $\mathrm{N}_{2}$-atmosphere for $12 \mathrm{~h}$. The volume of the mixture was reduced to $10 \mathrm{ml}$ in vacuo and the product allowed to stand at $4{ }^{\circ} \mathrm{C}$ overnight resulting in white crystals $(2.1 \mathrm{~g}$, yield 77\%), mp. 157-159 ${ }^{\circ} \mathrm{C}$ (EtOH). All spectroscopic analyses were in accordance with the structure and will be published elsewhere.

The cultures were analyzed after 3 weeks of cultivation, unless otherwise stated. Mycelia were separated from the liquid by filtration through $100 \mu \mathrm{m}$ nylon nets, dried between paper sheets, weighed and extracted with $70 \%$ methanol. The medium was extracted with ethyl acetate. The organic and aqueous phases were evaporated to dryness and the residues dissolved in $70 \%$ methanol. The resulting solutions were analyzed by HPLC.

\section{HPLC analysis}

HPLC was performed with a Beckman model 126 chromatograph equipped with a diode array detector 168 and an Ultrasphere ODS RP 18 column. Compounds were eluted by the following linear gradient: 0-1 min solvent A, 1- $21 \mathrm{~min}$ $20 \%$ methanol in solvent A, 21-40 min $80 \%$ methanol, 41-43 min $100 \%$ methanol; A: $0.1 \%$ TFA in $\mathrm{H}_{2} \mathrm{O}$. The detection wavelengths were 280 and 227 or $410 \mathrm{~nm}$. The identity of known compounds was verified by co-chromatography with synthetic and natural reference substances and by the UV-scans. The phenoxazinone references (2-acetylamino$3 H$-phenoxazin-3-one, 2-(2-hydroxyacetyl)-amino-3H-phenoxazin-3-one, 2-amino-8-hydroxy-3H-phenoxazin-3-one, 2-amino-8-hydroxy-3H-phenoxazin-3-one, 2-acetylamino-8hydroxy-3H-phenoxazin-3-one, 2-acetylamino-8-methoxy$3 H$-phenoxazin-3-one) were a gift from Dr. C. Werner, University of Zürich.

The major compound appearing in glucoside carbamate medium was isolated by HPLC using the column and the gradient described above. With 18 analytical HPLC runs 0.8 $\mathrm{mg}$ of the compound could be obtained. The solution was evaporated by vacuum centrifugation to dryness and the residue analyzed by $1 \mathrm{H}-\mathrm{NMR}$ and EI-HR-MS.

\section{Two dimensional Electrophoresis}

Two dimensional electrophoresis was performed with the BioRad Protean IEF Cell and the BioRad Mini Protean II Cell, using Ready Strip TM IPG strips pH 4-7 (BioRad). The mycelia were collected by filtration (100um nylon net), washed with distilled water, dried between paper sheets and weighed. They were vigorously mortared with quartz sand and the 6 - fold (w/v) amount of extraction buffer (9.5 M urea with $400 \mathrm{mg}$ Chaps, $150 \mathrm{mg}$ dithiothreitol, $80 \mu \mathrm{l} 50 \%$ n-hexyl- $\beta$-D-glucopyranoside, $40 \mu \mathrm{l} \quad 10 \%$
n-decyl-ß-D-maltopyranoside, $20 \mu \mathrm{l}$ 10\% SDS, $200 \mu \mathrm{l}$ ampholyte Pharmacia TM 3-10 for IEF, all per $10 \mathrm{ml}$ buffer). The homogenates were centrifuged at 20,000 $\mathrm{g}$ for $15 \mathrm{~min}$ at room temperature. $500 \mu \mathrm{l}$ of the supernatants were used for protein precipitation with ice-cold methanol $(1,5 \mathrm{ml} /$ $500 \mu \mathrm{l})$. The precipitates were centrifuged for $10 \mathrm{~min}$ $\left(20,000 \mathrm{~g}, 4{ }^{\circ} \mathrm{C}\right)$ and the pellets washed twice with $200 \mu \mathrm{l}$ icecold acetone. The pellets were dried to remove residual acetone and dissolved in $200 \mu \mathrm{l}$ extraction buffer. $50 \mu \mathrm{l}$ of the protein solutions were used for IEF, which was run with 50 $\mu \mathrm{A} / \mathrm{gel}$ strip and finished after 20,000 vh. The strips were previously equilibrated in equilibration buffer (6 M urea, $30 \%$ w/v glycerol, $2 \%$ SDS in $0.05 \mathrm{M}$ Tris- $\mathrm{HCl} \mathrm{pH} \mathrm{8.8)}$ with $100 \mathrm{mg}$ DTT / $10 \mathrm{ml}$ for $10 \mathrm{~min}$, followed by a $10 \mathrm{~min}$ equilibration in presence of iodoacetamide $(400 \mathrm{mg} / 10 \mathrm{ml})$. Per strip, $2 \mathrm{ml}$ of the buffers were used. The equilibrated strips were rinsed with distilled water for 2 seconds and used for SDS-PAGE (17.5\% gels) as the second dimension. The gels were stained with Coomassie Blue, destained and scanned. Major spots were excised for protein identification.

\section{Digest protocol}

Gel spots were repeatedly dehydrated and rehydrated prior to digestion by soaking them in dehydration (2:1 acetonitrile/25mM ammonium bicarbonate) and rehydration solutions (25mM ammonium bicarbonate) in turn. Spots were dehydrated four times. Following the fourth dehydration, the supernatant was removed and spots were dried in a vacuum centrifuge. Spots were then resuspended in $\sim 10 \mathrm{ng} / \mathrm{microliter}$ solution of trypsin in $25 \mathrm{mM}$ ammonium bicarbonate with $\sim 5 \mathrm{mM}$ calcium chloride. Small amounts of trypsin solution were added as the spots rehydrated. Once rehydrated, the spots were covered with a minimal volume of ammonium bicarbonate solution and incubated 4.5 hours at $37{ }^{\circ} \mathrm{C}$, and generated peptides were extracted by adding roughly twice the digest buffer volume of acetonitrile with $1 \%-2 \%$ formic acid. Samples were vortexed and then the peptidecontaining supernatant was transferred to new tubes, which underwent vacuum centrifugation to remove the organic solvent.

\section{In-gel Deglycosylation protocol}

A second round of samples underwent in-gel deglycosylation with PNGase F (Sigma P 7367) according to the manufacturer's instructions prior to tryptic digestion. In short, following destaining, excised spots were dried via vacuum centrifugation and then rehydrated with a PNGase F solution and incubated 30 minutes at $37^{\circ} \mathrm{C}$, water was added to cover the gel pieces and samples were incubated overnight at $37{ }^{\circ} \mathrm{C}$. The gel pieces were then repeatedly rinsed with water to remove residual PNGase F, and tryptic digests were performed as described above.

MS - Methods

LC MS/MS data were collected using a Q-ToF II tandem mass spectrometer coupled to a CapLC system fitted with a 75um NanoEase Atlantis dC18 analytical column and a 
Table 1 Series A: weight of mycelium after 6 weeks of incubations with compounds 1, 2, 3, 4, and 3 weeks of incubation with compounds $5,6,7,8,9$. Weight of control $0.441 \pm 0.04 \mathrm{~g}$ in average, data present average values and the standard deviations $(n=4)$.

\begin{tabular}{lcc}
\hline Compound & $\begin{array}{c}\text { Weight of mycelium (g) } \\
\text { cultured without sucrose }\end{array}$ & $\begin{array}{c}\text { Weight of mycelium (g) } \\
\text { cultured with sucrose }\end{array}$ \\
\hline BOA (1) & $0.143 \pm 0.029$ & $0.256 \pm 0.012$ \\
BOA-6-OH (2) & $0.145 \pm 0.021$ & $0.272 \pm 0.08$ \\
MBOA (3) & $0.117 \pm 0.05$ & $0.25 \pm 0.09$ \\
glucoside carbamate (4) & $0.136 \pm 0.03$ & $0.193 \pm 0.01$ \\
2-aminophenol (5) & $0.129 \pm 0.017$ & $0.11 \pm 0.03$ \\
2-acetamidophenol, AAP (6) & $0.146 \pm 0.055$ & $0.293 \pm 0.05$ \\
N-(2-hydroxyphenyl)malonamic & No growth & $0.272 \pm 0.07$ \\
$\quad$ acid, oHPMA(7) & no growth & no growth \\
2-amino-3H-phenoxazin-3-one (8) & $0.113 \pm 0.014$ & $0.11 \pm 0.02$ \\
N-(2-hydroxyphenyl)- $\beta$-D-gluco- & pyranosylamine, (9) &
\end{tabular}

NanoEase Symmetry300 C18 Trap column in a forward flushing configuration (Waters Corporation). All chromatographic solutions contained $0.1 \%$ formic acid. Peptide mixtures were separated with a gradient of $5-50 \%$ acetronitrile in water (Aldrich HPLC grade) over a 15 minute period, followed by column cleaning and re-equilibration.

Data were collected in survey mode using argon as a collision gas at a pressure of 4-5x10(-5) bar. Capillary voltage was $1.6 \mathrm{kV}$ and the cone voltage was $45 \mathrm{~V}$. The collision voltage was kept at $10 \mathrm{~V}$ during MS-ToF mode collection.

Multiply-charged precursor ions of sufficient intensity were fragmented in MSMS mode with collision voltage between 20 and 70 volts, depending on precursor charge and mass.

Multiple runs were performed with each sample. Peak files were generated by Masslynx3.5 (Waters Corp.) and de Novo sequencing was performed both with LutefiskXP version 1.0 (Richard S. Johnson) and ProteinLynx/Global Server2.1 (Waters Corp). Resulting de Novo sequences were visually checked and the highest scoring sequences were used to form queries for MSBLAST searches (Shevchenko et al. 2001).

\section{Results}

\section{Growth studies}

When the fungus was cultured in the complete medium (with sucrose) containing BOA (1), BOA-6-OH (2) or MBOA (3) at concentrations up to $10 \mu \mathrm{mol}$ growth was inhibited by about $40 \%$ in comparison to the control (table 1, series A). In the presence of the compounds growth started after a lag phase of one to two weeks. Without sucrose, mycelial growth was more strongly inhibited by the three compounds $\mathbf{1 , 2}$, and $\mathbf{3}$ (up to $70 \%$ )

Glucoside carbamate (4) displayed slightly stronger inhibition (up to $55 \%$ with sucrose, $70 \%$ without sucrose), and a longer lag phase was observed (up to three weeks).

The growth inhibition by 2 -aminophenol (5), compound (9) and 2-amino-3H-phenoxazin-3-one (8) was independent from the presence of sucrose. Mycelial growth was reduced to $25 \%$ of the control by $(\mathbf{5})$ and $(\mathbf{9})$. The strongest reduction (more than $90 \%$ inhibition) was found with 2 -amino- $3 \mathrm{H}$ phenoxazin-3-one (8). 2-Acetamidophenol (AAP, 6) and $\mathrm{N}$-(2-hydroxyphenyl) malonamic acid (oHPMA, 7) inhibited growth to a similar extent as observed with BOA (1) or BOA-6-OH (2) (both about 70\% without sucrose, 40-35\% with sucrose). The growth data are presented in table 1 .

Longer lag phases ( 2 up to 3 weeks) were accompanied by changes in the colony morphology: many small pellets were observed rather than the few large, fluffy colonies seen in the controls. Changes in colony morphology together with a propensity to generate conidia and particular chlamidospores were observed especially with MBOA, BOA-6$\mathrm{OH}$ and 2-amino-3H-phenoxazin-3-one. An alteration in the morphology of the hyphae was also observed (fig. 2). D. stemonitis formed discolored, swollen and twisted hyphae with numerous big, round chlamidospores as a reaction to unfavorable conditions (fig. 2 b) The presence of 2-amino-3H-phenoxazin-3-one, for example, caused also a simplification of sporulation structures. Formation of conidiophores was found on single hyphae and not in coremia (fig. $2 \mathrm{c}$ and d).

Accumulation of the compounds 1-4 within the mycelium was negligible, with concentrations in the pmol range (table 2), but it is likely that these low amounts act as priming agents, since shorter lag phases (less than one week) were observed in subsequent incubations when material from these cultures was used.

\section{Metabolism of compounds}

Benzoxazolinones and higher plant detoxification products

For studying compound metabolism, a series of incubations were carried out in the absence of sucrose with mycelia previously cultured in complete medium or without sucrose for depletion of $\mathrm{C}$-stores within the hyphae and metabolite levels are presented in table 2. BOA (1), BOA-6-OH (2), MBOA (3) and glucoside carbamate (4) were degraded. In the absence of sucrose, the final concentration of glucoside carbamate (4), MBOA (3) and BOA-6-OH (2) concentration was lower. The latter compound was completely degraded, 

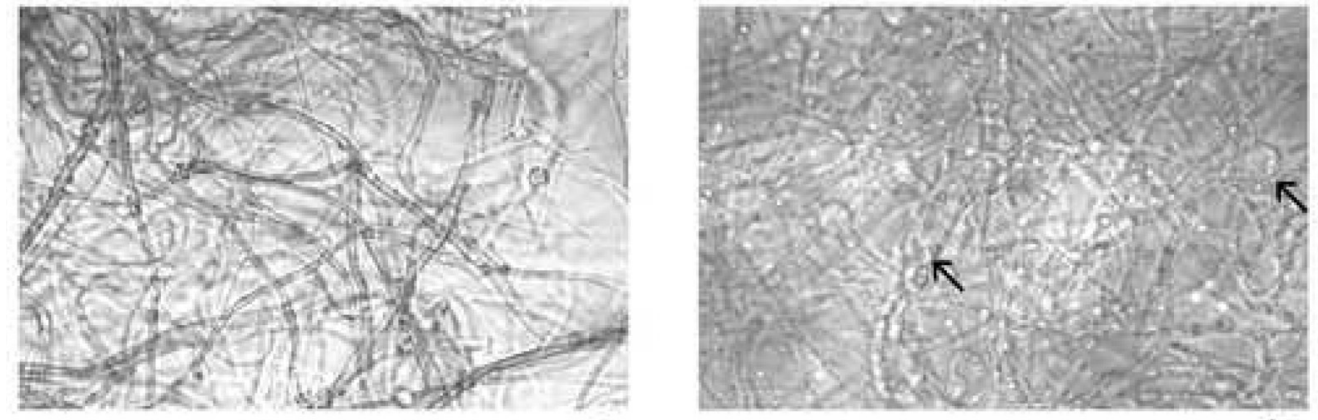

a
Fig. 2 Morphological changes of Doratomyces stemonitis mycelium in presence of phenoxazinone. A: mycelium, control (x 198); b: mycelium, grown in presence of phenoxazinone, with swollen hyphae and formation of chlamidospores (arrows); c: conidiophore on coremia, control (x 132); d: conidiophore formed without coremia in presence of phenoxazinone (x 198). All incubations were performed in complete medium (with sucrose)
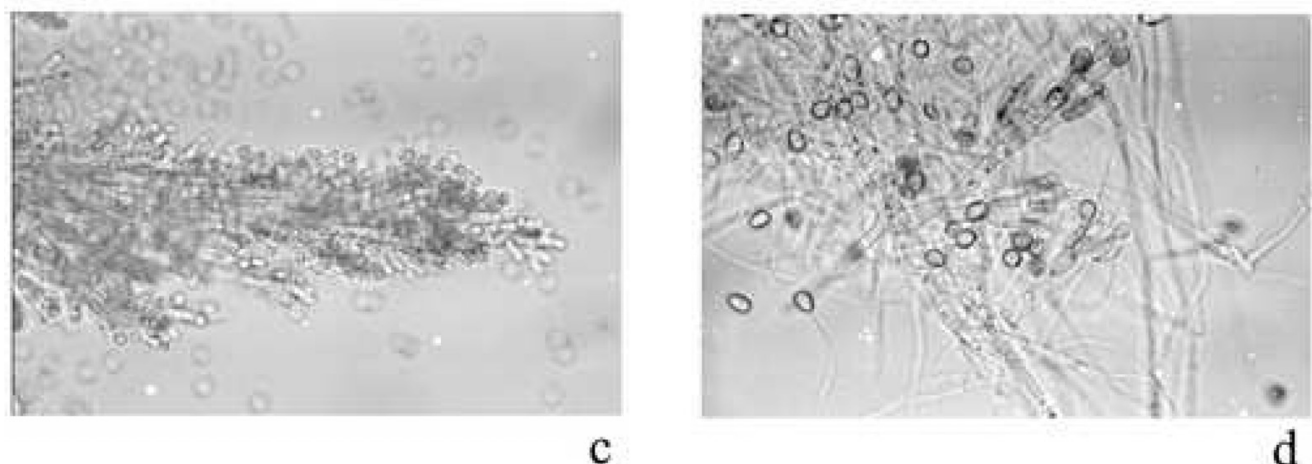

$\mathrm{c}$

Table 2 Series B: Metabolism of BOA and higher plant detoxification products. Amount of compound left in the medium $(\mu \mathrm{mol}),(\mathrm{n}=4)$. Incubation time: 6 weeks. Data present average values and standard deviations $(n=4)$.

\begin{tabular}{|c|c|c|c|c|c|}
\hline $\begin{array}{l}\text { Culture } \\
\text { In presence } \\
\text { of } 10 \mu \mathrm{mol}\end{array}$ & $\begin{array}{c}\text { Highest } \\
\text { Accumulation } \\
\text { pmol/mg } \\
\text { mycelium } \\
\text { (incubation } \\
\text { without sucrose) }\end{array}$ & $\begin{array}{c}\text { Highest } \\
\text { Accumulation } \\
\text { pmol/mg } \\
\text { mycelium } \\
\text { (incubation } \\
\text { with sucrose) }\end{array}$ & $\begin{array}{l}\text { Incubation in } \\
\text { presence of } \\
\text { sucrose, } \\
\text { Mycelium } \\
\text { from culture } \\
\text { with sucrose }\end{array}$ & $\begin{array}{l}\text { Incubation } \\
\text { without } \\
\text { sucrose, } \\
\text { Mycelium } \\
\text { from culture } \\
\text { with sucros }\end{array}$ & $\begin{array}{c}\text { Incubation } \\
\text { without sucrose, } \\
\text { Mycelium from } \\
\text { culture without } \\
\text { sucrose }\end{array}$ \\
\hline $\begin{array}{l}\text { BOA (1) } \\
\text { BOA-6-OH (2) } \\
\text { MBOA (3) } \\
\text { glucoside } \\
\text { carbamate(4) }\end{array}$ & $\begin{array}{c}83,5 \pm 6 \\
100,5 \pm 9,7 \\
\text { traces } \\
36 \pm 5,4\end{array}$ & $\begin{array}{c}46 \pm 7,6 \\
16,6 \pm 3,4 \\
\text { n.d. } \\
11,2 \pm 2,2\end{array}$ & $\begin{array}{c}4,12 \pm 0,22 \\
3,75 \pm 1,28 \\
5,45 \pm 0,65 \\
7,15 \pm 1,05 \\
\text { (BOA: traces) }\end{array}$ & $\begin{array}{c}3,45 \pm 0.37 \\
\text { traces } \\
2,27 \pm 0,64 \\
1,97 \pm 1,61 \\
(3,4 \pm 1,32 \mathrm{BOA})\end{array}$ & $\begin{array}{c}2,37 \pm 0.48 \\
\text { traces } \\
2,3 \pm 0,96 \\
0,95 \pm 0,64 \\
\text { (BOA: traces) }\end{array}$ \\
\hline
\end{tabular}

with only trace amounts remaining. From these experiments we conclude that $D$. stemonitis can use most of the compounds as a C-source (table 2, series B).

BOA-6-OH (2) was degraded without considerable accumulation of new compounds. Only traces of 2-acetylamino-7hydroxy-3H-phenoxazin-3-one were present. Interestingly, the largest amount of BOA (1) was metabolized via BOA-6-OH (2), which was found in the medium together with traces of 2-amino-3H-phenoxazin-3-one (8). MBOA (3) was diminished in the incubation medium without accumulation of any additional product. Neither BOA-6-OH (2) nor BOA (1) nor $3 \mathrm{H}$-phenoxazin-3-ones could be detected. Apparently, there are two different routes of BOA degradation, one via
BOA-6-OH (2) and another one by direct cleavage of the heterocycle. As accumulation of 2-amino-3H-phenoxazin-3ones was generally low and not adequate to explain the disappearance of BOA-6-OH (2) or BOA (1), accumulation of high levels of 2-aminophenol (5) amounts seems to be avoided.

Glucoside carbamate (4) was not metabolized directly (fig. 3, tab. 2). Instead, a compound with an UV spectrum and a retention time identical to BOA (1) appeared and could be isolated from the medium. Chemical analysis of this compound verified it to be BOA (1). Thus BOA represents an intermediate of glucoside carbamate degradation, which is further degraded to 2-aminophenol (5), a fraction 


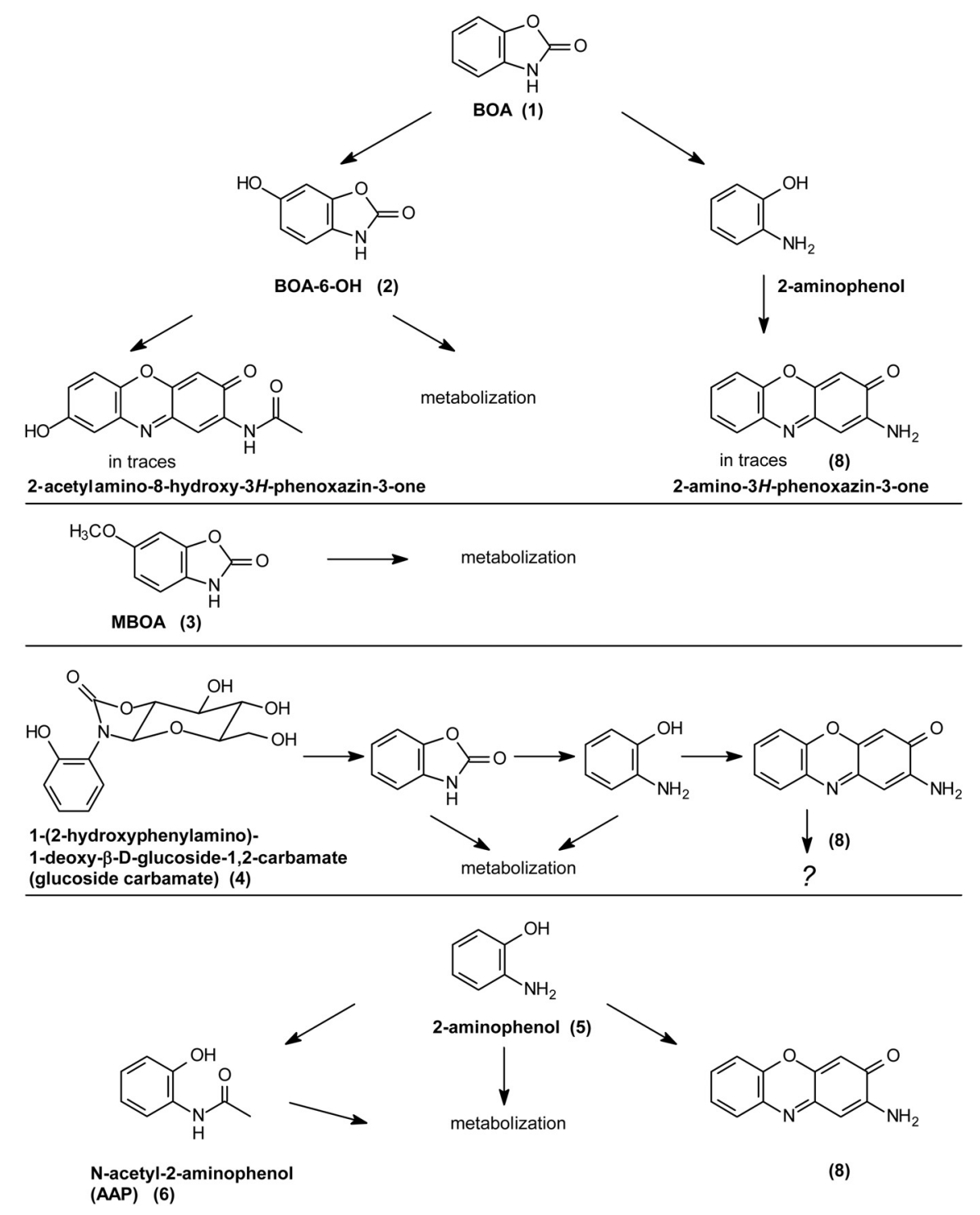

of which is detoxified by acetylation yielding 2-acetamidophenol (6), while a considerable amount is converted to 2amino-3H-phenoxazin-3-one (8). BOA-6-OH (2) was detectable only in traces in the medium. It is not clear why the hydroxylation of BOA (1) to BOA-6-OH (2) observed with $\mathrm{BOA}$ incubations does not occur prior to its further degradation in this pathway.

\section{Microbial degradation products}

In all incubations supplemented with 2-aminophenol (5), the compounds 2-acetamidophenol (AAP,6), 2-amino-3Hphenoxazin-3-one (8) and 2-acetylamino-3H-phenoxazin-3one could be found in high concentrations, indicating that a large amount of 2-aminophenol (5) was not directly degraded and only a part was detoxified via 2-acetamidophenol (6) production. Since 2-aminophenol (5) starts to dimerize to 2 -amino-3H-phenoxazin-3-one (8) immediately after application to the media, incubation conditions were very soon comparable with incubations that were directly started with 2-amino-3H-phenoxazin-3-one (8). Therefore it
Fig. 3 Metabolization of different BOA derivatives, higher plant and microbial detoxification products. was not possible to determine residual 2-aminophenol (5) concentrations at the end of the incubation period.

After three weeks of incubation with 2-aminophenol-N$\beta$-D-glucopyranoside ( 9) this synthetic compound could not be detected in the medium any more and only traces of 2-amino-3H-phenoxazinone (8) were present (table 3 , series C). In incubations with 2-acetamidophenol (AAP,6), 40 to $50 \%$ of it was degraded within the same incubation period. The fungus was able to hydrolyze malonamic acid from N-(2-hydroxyphenyl) malonamic (oHPMA, 7) acid resulting in traces of 2-amino-3H-phenoxazin-3-one (8). When $1 \mu \mathrm{mol}$ 2-amino-3H-phenoxazin-3-one $(\mathbf{8})$ was directly applied to the medium, most of it was obviously metabolized without considerable accumulation of UV-active intermediates. Figure 3 illustrates the degradation of the different compounds.

\section{Influence on major proteins}

Two dimensional electrophoresis with protein extracts from the mycelia that used the compounds as a C-source revealed alterations of the protein pattern (fig. 4). Several of the 


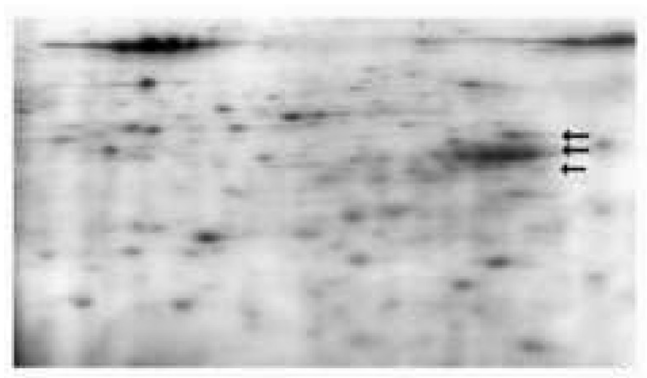

A

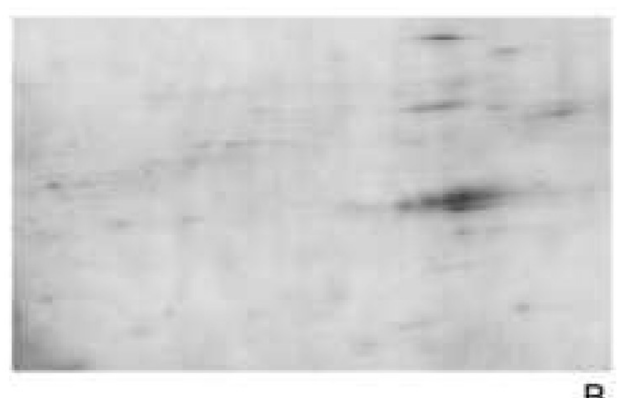

B
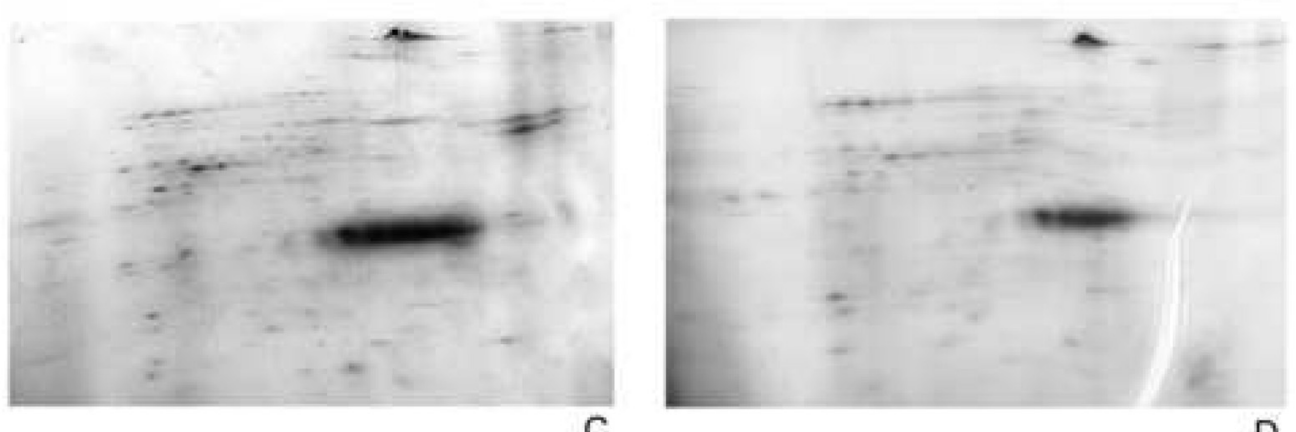

C

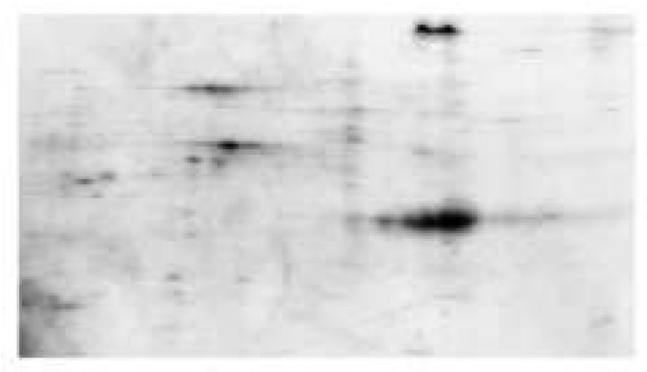

$\mathrm{E}$

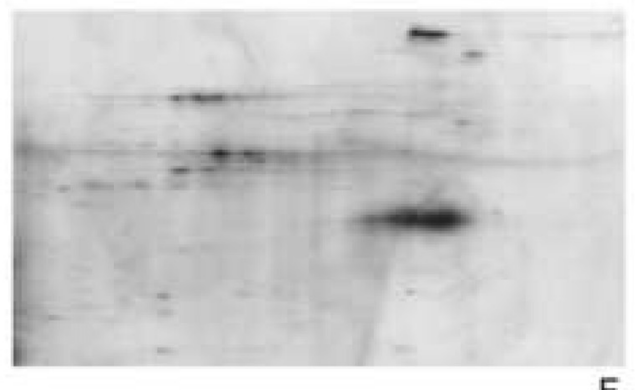

Fig. 4 Two-dimensional electrophoresis of D. stemonitis mycelia. A: control; after incubation with B: BOA; C: MBOA; D: BOA-6-OH, E: 2acetaminophenol, similar to 2aminophenol and phenoxazino ne incubation (data not shown); F: glucoside carbamate. The arrows (A) point to a group of proteins which were highly effected by the compounds and to minor spots adjacent to this row

Table 3 Series C: Metabolism of microbial and one synthetic BOA derived compounds, $\mu$ mol presents amount of compound left in the medium. Incubation time: 3 weeks. Data presents average values and standard deviations $(n=4)$.

\begin{tabular}{lcc}
\hline $\begin{array}{l}\text { Culture in presence } \\
\text { of } 10 \mu \mathrm{mol}\end{array}$ & $\begin{array}{c}\text { Incubation without sucrose, } \\
\text { Mycelium from culture } \\
\text { without sucrose }\end{array}$ & $\begin{array}{c}\text { Detectable degradation } \\
\text { products }\end{array}$ \\
\hline $\begin{array}{l}\text { 2-acetamido-phenol, AAP (6) } \\
\text { N-(2-hydroxyphenyl)malonamic } \\
\text { acid, oHPMA (7) }\end{array}$ & $5,7 \pm 0,25$ & Phenoxazinones (traces) \\
$\begin{array}{l}\text { 2-amino-phenoxazinone } \\
(\mathbf{1} \boldsymbol{\mu m o l )}(\mathbf{8})\end{array}$ & $6,3 \pm 0,58$ & Phenoxazinones (traces) \\
$\begin{array}{l}\text { N-(2-hydroxyphenyl) } \beta \text {-D-gluco- } \\
\text { pyranosylamine (9) }\end{array}$ & $2,9 \pm 0,54$ & Low amounts of unknown products \\
\hline
\end{tabular}

major proteins of the control samples were strongly diminished whereas others were new or increased. A group of major proteins in the $\mathrm{pH}$ range of 6 and a molecular weight range of 40-45 $\mathrm{kD}$ was especially affected. In the control samples this group consists of at least 9 spots, five of which (spot 3-7) are arranged in a row. Several small spots were adjacent to this row of proteins. The major spots were of special interest because they increased dramatically in abundance when the fungus was grown in presence of MBOA (3) and BOA detoxification products. The strongest increase was observed with MBOA (3) and to a lower extent with BOA-6-OH (2). Glucoside carbamate (4) and 2-aminophenol (5) (2-amino-3H-phenoxazin-3-one, 8) also caused some increase in abundance of the proteins while abundance of others decreased. The same was found with 2-acetamidophenol or H1 (9) (not shown). 
Table 4 Analyzed strongest de novo peptide sequences

\begin{tabular}{llc}
\hline LAATAHATA[YR] & 1144.59 & +2 \\
RAMPADALEETVVLAR & 1740.84 & +2 \\
[158.08]DRGDMLFR & 1166.55 & +2 \\
[158.09]AQYG[509.09]TQ & & \\
NDWAGHWR & 2355.94 & +3 \\
WDATAETVICDASFR & 1740.79 & +2 \\
[184.12]NSSLCGGGYTV & & \\
VESPLNTYWAVDLLHR & 3191.62 & +3 \\
[260.15]ENPDYFAEVFAK & 1688.82 & +2 \\
\hline
\end{tabular}

To elucidate the identity of major protein sensitive to BOA treatment, selected protein spots were excised and subjected to LC/MS/MS analysis. Though spots were strong, the initial sample digests resulted in very few fragmentation spectra. The strongest and most frequently observed precursor yielded de Novo sequences containing the subsequence NSSLCGGGY TVVESPLNTYWAVDLLHR, which hit fungal proteins during MSBLAST searching (Shevchenko et al. 2001). Searching with BLAST (Altschul et al. 1997) the following hits were obtained: Allergen Asp f2-like protein from Verticillium dahliae, EAA73422.1 hypothetical protein from Gibberella zeae, EAA51681 hypothetical protein from Magnaporthe grisea. The repeated observation of this peptide mass in multiple samples indicates that other spots in the row are isoforms of one protein.

The first SwissProt entry among the BLAST hits for this peptide is the pH-regulated antigen PRA1 precursor from Candida albicans (P87020) a secreted glycoprotein. The de novo peptide observed aligns to a region between proposed glycosylation sites on PRA1. We therefore performed an in-gel deglycosylation reaction prior to digestion and analysis of subsequent samples. The strongest de novo peptide sequences from this analysis were used as queries for MSBLAST and sequences matching Trypsin and PNGase F were removed (table 4). The resulting MSBLAST matched six new peptides to Allergen Asp f2-like proteins from various fungi. A multiple alignment of the six best protein hits and the fit of the seven de novo sequences to the alignment is shown in figure 5 . The observed peptides constitute roughly $30 \%$ of the likely protein sequence. The first aspartate in the peptide sequence WDATAETVICDASFR aligns with a conserved asparagine which is annotated as an N-glycosylated site in the annotated proteins. This conflict is consistent with the deamidation reaction that occurs when PNGase F removes the N-glycosylation.

In the course of analysis, spots adjacent to the main row were also digested and analysed and a de novo peptide matching Aspartate protease was found.

\section{Discussion}

Detoxification of BOA (1) and MBOA (3), described for several fungi e.g. Fusarium verticillioides, Fusarium subglutinans and Gaeumannomyces graminis (Glenn et al. 2003, 2002, 2001; Yue et al. 1998; Friebe et al. 1998, results in the major detoxification products $\mathrm{N}$-(2-hydroxyphenyl) malonamic acid
(oHPMA, 7) and N-(2-hydroxy-4 methoxyphenyl)-malonamic acid. 2-Acetamidophenol (AAP, 6) is thought to represent a branch product synthesized by $F$. verticillioides. Doratomyces stemonitis does not produce oHPMA (7), but 2-acetamidophenol (AAP, 6) is detectable under the growth conditions used when media were supplemented with 2 -aminophenol $(\mathbf{5})$ or glucoside carbamate (4). Thus, D. stemonitis does not seem to possess the same detoxification capacity as, for example, Fusarium verticillioides. However, D. stemonitis can use the compounds BOA (1), MBOA (3), and BOA-6-OH (2) a $\mathrm{C}$-source at concentrations of up to $10 \mu \mathrm{mol}$.

Degradation of the chemically relatively stable 2 -amino$3 H$-phenoxazin-3-one (8) seems to be a challenge for $D$. stemonitis, as indicated by the extremely slow growth, independent of the presence or absence of sucrose. All the compounds tested, except for MBOA, finally led to the accumulation of 2-aminophenol (5), which underwent easily dimerization to 2-amino-3H-phenoxazin-3-one (8), some of which was further converted. From N-(2-hydroxyphenyl) malonamic acid (oHPMA, 7) and from 2-acetamidophenol (AAP,6) the acetyl group and the malonyl group, respectively, can be hydrolyzed prior to further metabolization. Clearly, D. stemonitis has the capacity to degrade 2-amino$3 H$-phenoxazin-3-one (8) when applied at low concentrations, but the activated metabolic machinery results in severe growth inhibition and a reduced biomass.

In contrast to $D$. stemonitis, $F$. verticillioides is able to grow in the presence of significantly higher concentrations of 2-aminophenol (5), and its detoxification appears to be completed within 3 days ( Glenn et al. 2003, 2002, 2002; Yue et al. 1998). This indicates tremendous differences in the ability of fungi to cope with allelopathic compounds, such as BOA (1).

Detoxification of the benzoxazolinones is thought to enhance the ecological fitness of fungi that get in contact with plants containing benzoxazinoids (Glenn et al. 2003). The same should be true for higher plants. As already mentioned, a portion of the higher plant detoxification products is exuded by the roots. D. stemonitis has the capacity to cleave the glucose moiety from glucoside carbamate (4), a more complex enzymatic reaction than the simple hydrolysis catalyzed by a common $\beta$-glucosidase. BOA degradation may start at the moment when the glucoside carbamate is no longer available. In fact, the BOA concentration might even increase in the rhizosphere due to the activity of fungi, which may regenerate the original phytotoxic compound from the non-toxic metabolite glucoside carbamate (4). As a result the allelopathic impact that BOA may exert on the plants via the rhizosphere may temporarily increase.

With regard to the fungus living in the rhizosphere, BOA (1) can be reabsorbed by the roots of a higher plant that is able to synthesize glucoside carbamate (4) and to exude it again. When re-absorption stops, BOA regenerated from glucoside carbamate may be directly degraded to 2-aminophenol (5) and phenoxazinones. On the one hand, glucoside carbamate (4), which is not toxic to higher plants at concentrations up to $1 \mathrm{mM}$, has the potential to inhibit growth of $D$. stemonitis as a result of 2 -amino- $3 H$-phenoxazin-3-one formation. On the other hand, the intermediate 2-aminophenol (5) can be converted to 2-acetamidophenol (AAP,6) or N-(2-hydroxyphenyl) malonamic acid (oHPMA, 
CLUSTAL $W$ (1.82) multiple sequence alignment

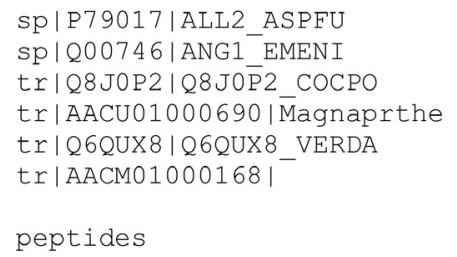

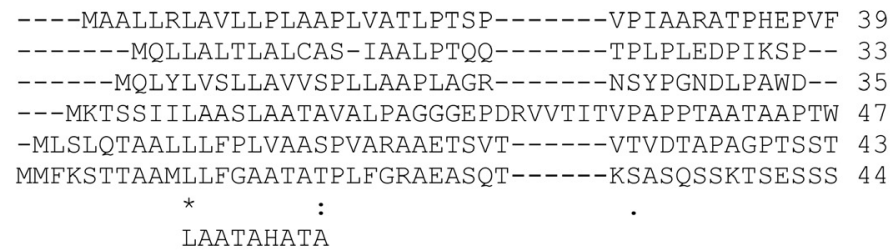

FSWDAGAVTSFPIHSSCNATQRRQIEAGLNEAVELARHAKAHILRWGNES 89 ---------FPTHHSCNATEOROLATALOETVTLAEHAKDHTLRWGNES 73 ----HGAVTQYPIHDSCNVTERRLIERGLQDAITLANHAKKHVLRFSNSS 81 N-WREGAVDSYPIHSSCNGTERLOLARALDETVSLAROARDHILRFGKTS 96 YNWAEGWKANFPIHQSCNITLRTQLEAALAETMTIAAHARDHLL-HNPKS 92 YNWSEGWTKDYPIHQSCNATLRHQLSSALDETVQLAQHAKDHILRHGHKS 94

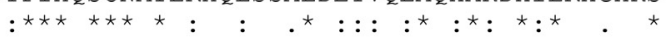
RAMPADALEETVVLAR

EIYRKYFGNRPTMEAVGAYDVIVNGDKANVLFRCDNPDGNCA-LEGWGGH 138 AIYRKYFGDRPSLTAIGAYDI IVNGNPDNILFRCDNPDGNCA-LEGWGGH 122 SIYRKYFGNAPSGEVIGNLDRIVNADRAKTLFRCDNPDGNCK-LPKWGGH 130 SLYSKYFGNASTAEPVGWYHKLVGGDKAGLLFRCDDIDGNCH-QEGWGGH 145 ELATKFFGNQSVAGPIGWYSKVVSTDKSEMLFRCDDPDRNCATQDGWAGH 142 EFFTKYFGNASTSOPIGWYDRVVNADKTGVLFRCDDPDKNCATODAWAGH 144

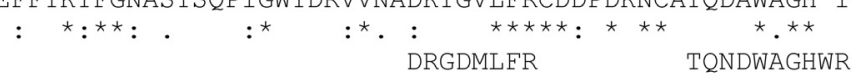

WRGANATSETVICDRSYTTRRWLVSMCSQGYTVAGSETNTFWASDLMHRL 188 WRGENASDETVICELSYTTRRSLSTMCSQGYTISEWETNTFWAGDLLHRL 172 WRGSNATGETVICPLSYTTRLFLEHFCTRGYTVAGSPLNTYFGTDLLHRL 180 WRGENATSETVICPLSYTTRKSLEGLCGFGYTVAAGKLNTFWAGDLMHRI 195 WRGSNATOETVICDLSYEIRRPLAALCGGGYTVAESKLNTYWATDLLHRA 192 WRGDNATSETVICPLSFEIRRNLDSVCNLGYTVANSKLNTFWATDLLHRV 194

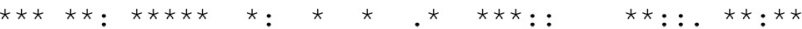
WR WDATAETVICDASFR NSSLCGGGYTVVESPLNTYWAVDLLHR

YHVPAVGQGWVDHFADGYDEVIALAKSNGTESTHDSEAFEYFALEAYAFD 238 YHMPAIGQGLVEHYADGYEGVLELAEGNRTEAVHDSETLQYFALEVYAYD 222 YHLPAIGEGHIEHFSDSYEDVLELGAHNSSFAVRDSNALQYFAADVYGFD 230 FHLEPVGEGVLEHYADSHAECLELAKSDPAKAARNSHTLQYFALDVYAYD 245 FHLPGISDGIIDHYAEDYAEALKLAATEPELSIIDSDTLQYFAIEAYAYD 242 LHVPI ISEKTVDHFAENYTDAIALAKSDPSKSVIDSDALQYFAIDVWAYD 244

${ }^{\star}: \quad:: \quad::^{\star}:::: \quad:{ }^{\star} . \quad: \quad:{ }^{\star} .:::^{\star \star}{ }^{\star}: .::^{\star}$ DYFAEVFAK

IAAPGVGCAGESHGPDQ-GHDTGSASAPASTSTSSSSSGSGSGATTTPTD 287 VAVPGIGCVGGEEEND--GQGEEQTEEPAQDDQQDE-------------- 256 IAVPGIGCAG-----------TPSPKPSTTSQPPA------------- 254 IALPGEGCAGKSPSASSDGGHSTPSPIPASPPTOTS-_--_--_----- 281 IAIPGVGCPGEKPIIDTAAGTSTAAPTTTTASDASG------------ 278 IAAPGEGCTGE---VEDETEEEKPTATKSDSSKPSA------------- 277

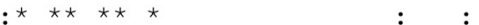

Fig. 5 Multiple alignment of the six best protein hits and the fit of the de novo sequences of analyzed peptides from D. stemonitis protein. The glycosylation site found in one D. stemonitis peptide is in boldface. ASPFU: Aspergillus fumigatus; EMENI: Emericella nidulans (Aspergillus nidulans); COCPO: Coccidioides posadasii; Magnaprthe: Magnaporthe grisea; VERDA: Verticillium dahlia; AACN01000168: Gibberella zeae (Fusarium graminearum) 
7) by other species existing in the same environment. Thus, $\mathrm{BOA}$, its derivatives and phenoxazinones can be finally degraded by microorganisms that act in concert. The ability or inability to metabolize benzoxazinoids could affect the diversity of the microbial community of the rhizosphere, in the worst case in favor of BOA-insensitive pathogens. Carter et al. (1999) assumed an influence of avenacin sensitive and insensitive cereal-root-colonizing fungi on the special microbial community. Similarly, benzoxazinoids and related compounds may cause shifts in the species composition of micro-organisms. The ability of micro-organisms to degrade the bioactive compounds contribute to their relatively short existence in the soil. The resulting soil decontamination is of ecological importance, since possible shifts in the species composition might be reversible in case of crop rotations.

Degradation of BOA, its derivatives and detoxification products is accompanied by a metabolic transition of the fungus as evident from the alterations in the abundance of major proteins on 2D gels. The strong accumulation of a group of proteins with similarity to Asp f2-like protein from Verticillium dahliae may be in fact a stress response of the fungus to the presence of the compounds in the culture medium (Banerjee et al. 1998; Wang et al. 2004). At present, it is unknown whether the protein from Doratomyces stemonitis has effects on plants or animals. The sequence similarity to Asp f2 (Aspergillus fumigatus) and Asp f2-like protein from Verticillium dahliae could imply a similar activity. The analyzed peptides from the Doratomyces stemonitis protein show also a high degree of sequence homology to ASPND1 (Emericella nidulans), to AY170477 protein from Coccidioides posadasii, to the Fusarium graminearum (Gibberella zeae) protein gi42550795, and to PRA1 antigen from Candida albicans. All these proteins are glycoproteins with several glycosylation sites. Aspergillus fumigatus is associated with diseases in humans and animals, Emericella nidulans is an agent of diverse infections in humans and Coccidioides posadasii a respiratory pathogen in humans. PRA 1 is an antigen from Candida albicans, which causes superficial infections of skin and mucosae, whereas Verticillium dahliae, Magnaporthe grisea (rice blast fungus) and Fusarium graminearum are plant pathogens. Asp 12 protein, a major allergen of A. fumigatus, presents an endo-1,3- $\beta$-glucanase (Fontaine et al. 1997). It is rather likely that all the proteins are glucanases explaining their presence in fungi that belong to quite different taxonomic groups. Glucanases are supposed to have fundamental functions in fungal metabolic activities, such as adaptation to stress conditions and/or in fungal development. The enzymes seem to be required for bud initiation, cell expansion, cell conjugation, and sporulation (Cenamor et al. 1987; Moy et al. 2002). 1,3- $\beta$-Glucan is a dominant polysaccharide in fungal cell walls. Glucanases are therefore essential for continuous rearrangements of 1,3 glucans accompanying cell wall degradation and reconstruction during the development and perhaps during the construction of chlamidospores. Surface located PRA1, a glycoprotein with motifs characteristic of secreted proteins, seems to have a role in morphogenesis as deletion of the gene resulted in temperature dependent defects of hyphae formation (Sentandreu et al. 1998). The observed changes in hyphae and colony morphology as well as the formation of chlamidospores when D. stemonitis is exposed to BOA derivatives, such as MBOA and BOA-6-OH or phenoxazinone may point to a glucanase function.

D. stemonitis is a saprotrophic fungus, but it is suspected to be the causal agent for speck rot on potatoes. Abiotic and biotic stress conditions, such as exposure to allelochemicals, starvation, mineral deficiency, and especially combinations of these conditions might enhance or generate pathogenicity of the fungus, which is also known as a potential pathogen to humans. Thus, the application of benzoxazolinones for weed control in agricultural systems might have unexpected effects.

\section{Acknowledgement}

We thank Dr. C. Werner, University of Zürich for phenoxazinone reference substances. M.S. and A.G. thank the BMBF, Internationales Büro for financial support of the cooperation project between the University of Bonn, Germany and the National University of Agriculture, Kiew, Ukraine.

\section{References}

Alipieva KI, Taskova RM, Evstatieva LN, Handjieva NV, Popov SS (2003) Benzoxazinoids and iridoid glucosides from four Lamium species. Phytochemistry 64:1413-1417

Altschul SF, Madden TL, Schäfer AA, Zhang J, Zhang Z, Miller W, Lipman DJ (1997) Grapped BLAST and PSI-BLAST: a new generation of protein database search programs. Nucleic Acids Res. 25:3389-3402

Banerjee B, Greensberger PA, Fink JN, Kurup VP (1998) Immunological characterization of Asp f2, a major allergen from Aspergillus fumigatus associated with allergic bronchopulmonary asperillosis. IAI 66: 5175-5182

Barnes P, Putnam AR (1987) Role of benzoxazinones in allelopathy of rye (Secale cereale L.). J Chem Ecol 13: 889-906

Baumeler A, Hesse M, Werner C (2000) Benzoxazinoids-cyclic hydroxamic acids, lactams, and their corresponding glucosides in the genus Aphelandra (Acanthaceae). Phytochemistry 53: $213-222$

Bravo HR, Lazo W (1996) Antialgal and antifungal activity of natural hydroxamic acids and related compounds. J Agric Food Chem 44: 1569-1571

Carter JP, Spink J, Cannon PF, Daniels MJ, Osbourn AE (1999) Isolation, characterization, and avenacin sensitivity of a diverse collection of cereal-root-colonizing fungi. Appl Environ Microbiol 65: 3364-3372

Cenamor R, Molina M, Galdona J, Sanchez M, Nombela C (1987) Production and secretion of Saccharomyces cerevisiae B-glucanases: differences between protoplast and periplasmic enzymes. J Gen Microbiol 133: 619-628

Fontaine T, Hartland RP, Beauvais A, Diaquin M, Latge J-P (1997) Purification and characterization of an endo-1,3- $\beta$-glucanase from Aspergillus fumigatus. Eur J Biochem 243:315-321

Friebe A, Vilich V, Hennig L, Kluge M, Sicker D (1998) Detoxification of benzoxazolinone allelochemicals from wheat by Gaeumannomyces graminis var. tritici, G. graminis var. graminis, G. graminis var. avenae, and Fusarium culmorum. Appl Environ Microbiol 64:2386-2391

Friebe A, Wieland I, Schulz M (1996) Tolerance of Avena sativa to the allelochemical benzoxazolinone. Degradation of BOA by root-colonizing bacteria. J Appl Bot 70:150-154

Gagliardo RW, Chilton, WS (1992) Soil transformation of $2(3 H)-$ benzoxazolinone of rye into phytotoxic 2-amino-3H-phenoxazinone-3-one. J Chem Ecol 18: 1683-1691

Gierl A. Frey, M (2001). Evolution of benzoxazinone biosynthesis and indole production in maize. Planta 213: 493-498 
Glenn AS, Meredith FI, Morrison III WH, Bacon CW (2003) Identification of intermediate and branch metabolites resulting from biotransformation of 2-benzoxazolinone by Fusarium verticillioides. Appl Environ Microbiol 69:3165-3169

Glenn A E, Gold SE, Bacon CW (2002) Fdb1 and Fdb2, Fusarium verticillioides loci necessary for detoxification of preformed antimicrobials from corn. Mol Plant-Microbe Interact 15:91-101

Glenn AE, Hinton DM, Yates IE, Bacon CW (2001). Detoxification of corn antimicrobial compounds as the basis for isolating Fusarium verticillioides and some other Fusarium species from corn. Appl Environ Microbiol 67:2973-2981

Hofmann D, Knop M, Hao H, Hennig L, Sicker D, Schulz M. (2006). Glucosides from MBOA and BOA detoxification by Zea mays and Portulaca oleracea. J Nat Prod 69:34-37

Macias FA, Oliveros-Bastidas A, Marin D, Castellano D, Simonet A.M., Molinillo JMG (2005) Degradation studies on benzoxazinoids. Soil degradation dynamics of (2R)-2- $\beta$-D-glucopyranosyl-4-hydroxy $(2 \mathrm{H})$-1,4-phenoxazin-3-(4H)-one (DIBOA-Glc) and its degradation products, phytotoxic allelochemicals from Gramineae. J Agricult Food Chem 53: 538-548

Moy M, Li HM, Sullivan R, White Jr JF, Belanger F C (2002) Endophytic fungal $\beta$-1,6-glucanase expression in the infected host grass. Plant Physiol 130:1298-1308

Morrissey JP, Osbourn AE (1999) Fugal resistance to plant antibiotics as a mechanism of pathogenesis. MMBR 63: 708-724

Schulz M, Wieland I (1999) Variations in metabolism of BOA among species in various field communities - biochemical evidence for co-evolutionary processes in plant communities? Chemoecology 9:133-141

Sentandreu M, Lorza MV, Sentandreu R, Fonzi WA (1998) Cloning and Characterization of PRA1, a gene encoding a novel pH-regulated antigen of Candida albicans. J Bacteriology 180 282-289

Shevchenko A, Sunyaev S, Loboda A, Shevchenko A, Bork P, Ens W, Standing KG (2001)

Charting the proteomes of organisms with unsequenced genomes by MALDI-quadrupole time-of-flight mass spectrometry and BLAST homology searching. Anal Chem 73:1917-26

Received 28 April 2006; accepted 2 August 2006.

Published Online First 12 January 2007.
Sicker D (1989) A facile synthesis of 6-methoxy-2-oxo-2,3-dihydrobenzoxazole. Synthesis 875-876

Sicker D, Frey M, Schulz M, Gierl A (2000) Role of natural benzoxazinones in the survival strategies of plants. Pp 319-346 in Jeong KW (ed) International Review of Cytology - A Survey of Cell Biology Vol. 198. Academic Press

Sicker D, Schneider B, Hennig L, Knop M, Schulz M (2001) Glucoside carbamate from benzoxazolin-2 $(3 H)$-one detoxification in extracts and exudates of corn roots. Phytochemistry 58: 819-825

Sicker D, Schulz M (2002) Benzoxazinones in plants: occurrence, synthetic access and biological activity. Pp 185-232 in Attaur-Raman (ed) Studies in Natural Product Chemistry 27. Bioactive Natural Products Part $\mathrm{H}$

Wang JY, Cai Y, Gou JY, Mao YB, Xu YH, Jiang WH, Chen XY (2004) VdNEP, an elicitor from Verticillium dahliae, induces cotton plant wilting. Appl Environ Microbiol 70: 4989-4995

Wieland I, Kluge M, Schneider B, Schmidt J, Sicker D, Schulz M (1998) 3- $\beta$-D-Glucopyranosyl-benzoxazolin-2(3H)-one - A detoxification product of benzoxazolin2 $(3 H)$-one in oat roots. Phytochemistry 48:719-722

Wieland I, Friebe A, Kluge M, Sicker D, Schulz M (1999) Detoxification of benzoxazolinone in higher plants. Pp 79-88 in Macias FA, Galindo JCG, Molinillo JMG, Cutler HG (eds) Recent Advances in Allelopathy - A Science for the Future Vol 1 Cadiz SAT

Yue Q, Bacon CW, Richardson DM (1998) Biotransformation of 2-benzoxazolinone and 6-methoxy-benzoxazolinone by Fusarium moniliforme. Phytochemistry 48:451-454

Zikmundova M, Drandarov K, Bigler L, Hesse M, Werner C (2002a) Biotransformation of 2-benzoxazolinone and 2-hydroxy-1,4benzoxazin-3-one by endophytic fungi isolated from Aphelandra tetragona. Appl Environ Microbiol 68: 4863-4870

Zikmundova M, Drandarov K, Hesse M, Werner C (2002b) Hydroxylated 2-amino-3H-phenoxazin-3-one derivatives as products of 2-hydroxy-1,4-benzoxazin-3-one (HBOA) biotransformation by Chaetosphaeria sp., an endophytic fungus from Aphelandra tetragona. Z Naturforsch 57C:660-665 